\title{
Syndromic surveillance in companion animals utilizing electronic medical records data: development and proof of concept
}

Philip H Kass, Hsin-Yi Weng, Mark A. L. Gaona, Amy Hille DVM MPH DACVPM, Max H Sydow, Elizabeth M Lund, Peter J Markwell

In an effort to recognize and address communicable and point-source epidemics in dog and cat populations, this project created a near real-time syndromic surveillance system devoted to companion animal health in the United States. With over 150 million owned pets in the U.S., development of such a system is timely in light of previous epidemics due to various causes that were only recognized in retrospect. The goal of this study was to develop epidemiologic and statistical methods for veterinary hospital-based surveillance, and demonstrate its efficacy by detection of simulated foodborne outbreaks using a database of over 700 hospitals.

Data transfer protocols were established via a secure file transfer protocol site, and a data repository was constructed predominantly utilizing open-source software. The daily proportion of patients with a given clinical or laboratory finding was contrasted with an equivalent average proportion from a historical comparison period, allowing construction of the proportionate diagnostic outcome ratio and its confidence interval for recognizing aberrant heath events. A five-tiered alert system was used to facilitate daily assessment of almost 2,000 statistical analyses. Two simulated outbreak scenarios were created by independent experts, blinded to study investigators, and embedded in the 2010 medical records. Both outbreaks were detected almost immediately by the alert system, accurately detecting species affected using relevant clinical and laboratory findings, and ages involved. Besides demonstrating proof-in-concept of using veterinary hospital databases to detect aberrant events in space and time, this research can be extended to conducting post-detection etiologic investigations utilizing exposure information in the medical record. 


\section{Syndromic Surveillance in Companion Animals Utilizing Electronic Medical Records Data: Development and Proof of Concept}

7

8

9

10

11

12

13

14

15

16

17

18

19

20

21

22

23

24

25

26

27

28

29

30

31

32

33

34

35

36

37

38

39

40

41

42

43

44

45

46
Philip H. Kass ${ }^{1 *}$

phkass@ucdavis.edu

Hsin-Yi Weng ${ }^{1}$

weng9@purdue.edu

Mark A. L. Gaona ${ }^{1}$

mgaona@ucdavis.edu

Amy Hille ${ }^{2}$

Amy.hille@banfield.net

Max Sydow ${ }^{2}$

max.h.vonsydow@gmail.com

Elizabeth M. Lund ${ }^{2}$

elizabeth.lund@banfield.net

Peter J. Markwell ${ }^{3}$

peter.markwell@effem.com

${ }^{1}$ Department of Population Health and Reproduction, School of Veterinary Medicine, University of California, Davis, CA 95616, USA

2 Banfield Applied Research and Knowledge Team, Banfield Pet Hospital, 8000 NE Tillamook St, Portland, OR 97213, USA

${ }^{3}$ Mars Global Food Safety Center, Huairou, Beijing, P.R. China, 101407

${ }^{*}$ Corresponding author: Philip H. Kass, Department of Population Health and Reproduction, School of Veterinary Medicine, University of California, Davis, CA 95616, USA. phkass@ucdavis.edu . (530) 752-8631. 


\section{Introduction}

48

49

50

51

52

53

54 55

56

57

58

59

60

61

62

63

64

65

66

67 68 syndromes or diseases in companion animals on a national scale in the United States.

Surveillance provides the key linkage between naturally occurring disease or syndrome occurrence and its real-time recognition (Henning, 2004; May, Chretien \& Pavlin. 2009; Wójcik et al. 2014). Multiple approaches to the conduct of surveillance exist, depending in part on whether measurement of incidence is possible (as in population- based active surveillance) or not (as in hospital-based or passive surveillance). If a preponderance of evidence points to an actual disease cluster, an epidemiologic outbreak investigation should be immediately initiated: the sooner the investigation begins following a sudden increase in disease frequency, the more likely that the source of the outbreak can be identified and an intervention implemented (Rothman, 1990).

The last decade has seen an increase in implementation of surveillance systems both in human populations (primarily to detect pandemic infectious disease (e.g., H1N1 influenza, SARS) and bioterrorism events (Drewe et al., 2012; Milinovich et al., 2014)) and animal populations (Dórea, Sanchez \& Revie, 2011). Although these systems alone do not have immediate applicability to companion animal populations, there has been interest in the United Kingdom and United States in monitoring zoonotic disease in such populations (Day et al., 2012; Glickman et al., 2006; Halliday et al., 2007; Maciejewski et al., 2007; Shaffer, 2007; Tierney et al., 2009). While disease surveillance has been performed to a limited extent in pet animals (notably in the United Kingdom's SAVSNET and VetCompass initiatives (The Small Animal

6 Veterinary Surveillance Network, 2015; Health Surveillance for UK Companion Animals, 2015),

7 there have been no efforts in the last several decades to conduct real-time surveillance for 
Both infectious and non-infectious disease epidemics have been documented in pet

70 animal populations in the United States over the last decade (AVMA, 2003; Puschner \&

71 Reimschuessel R, 2011; CDC, 2015). One well-established example is injection site sarcomas in

72 cats caused by certain commonly used vaccinations. This epidemic was fortuitously recognized

73 not through any surveillance mechanism, but through astute observation of a temporal increase in

74 the absolute number of cases, as well as an increase in proportionate diagnostic morbidity, at a

75 single tertiary care hospital's pathology department (Hendrick \& Goldschmidt, 1991). Given

76 that this epidemic was national in scope and not confined to a single vaccine manufacturer or

77 brand, and that certain vaccines are known to increase the incidence of sarcomas two to five-fold

78 (Kass et al., 1993), it is possible that it would have been detected by a surveillance system, had

79 one been in place, that included this specific type of cancer as a diagnostic endpoint.

This underscores a singular point in surveillance methodology: that it can be difficult to

81

82

83

84

85

86

87

distinguish "signal" (real events) from "noise" (normal or endemic background frequency of events). The strength of a surveillance system adaptive to companion animal populations thus depends on a number of factors, including: 1) the population size; 2) the magnitude of the causal effect of the risk factor; 3) the prevalence of exposure to the risk factor in the population; and 4) the baseline incidence of the outcome(s). The sensitivity of a surveillance system could be considerably improved if statistical measures were stratified by age, underscoring how active surveillance is more than real-time data mining, but also utilizes knowledge of health and disease to ask the appropriate queries and interpret the findings in a veterinary medical context.

A paradigmatic example of a point source foodborne outbreak in a pet population is the epidemic of nephrotoxicosis from ingestion of pet food adulterated with melamine in 2007 (Brown et al., 2007). Although this was not initially discovered through active surveillance, had 
92 such a system focusing on syndromic and diagnostic morbidity been in place it would have had a

93 very high probability of detecting the epidemic because: 1) the magnitude of the causal effect

94 was large, even though the incidence of nephrotoxicosis was relatively low; 2) the prevalence of

95 melamine in pet food diets was high; 3) the outcome was relatively specific, both as a diagnosis

96 (acute renal disease) and as a laboratory finding (hypercreatininemia); and 4) the outcome was of

97 sufficient severity that owners whose pets were under routine veterinary care were strongly

98 motivated to have sought care. Again, the sensitivity of such a surveillance system could have

99 been considerably enhanced by examining age strata, as the baseline incidence of both the

100 laboratory finding and the diagnostic outcome would have been particular rare (i.e., prior to

101 exposure to melamine) in younger age groups.

102 The goal of this research was to establish protocols devoted to near real-time surveillance

103 of dog and cat syndrome occurrence utilizing the electronic medical records of over 700

104 networked primary care veterinary hospitals in the United States, which are estimated to see

105 approximately $0.6 \%$ and $3 \%$ of the owned cat and dog populations in the United States,

106 respectively (Trevejo R, pers. comm., 2015; AVMA, 2012). This study’s approach builds upon

107 the classical epidemiological principle of estimating the proportional mortality ratio (PMR),

108 which contrasts the proportion of deaths from a particular cause in an exposed group with that of

109 an unexposed group (Miettinen \& Wang, 1981). This construct has been extended to

110 surveillance of adverse pharmacologic outcomes in non-hospital surveillance settings through the

111 proportional reporting ratio (PRR) (Rothman et al., 2004). The current study uses the

112 proportionate diagnostic outcome ratio (PDOR), a new but related metric that differs from the

113 PMR and PRR by utilizing medical findings by health care providers instead of causes of death

114 or adverse pharmacologic outcomes, respectively, and by treating time and geographic region as 
115 the exposures of interest. It adheres to the epidemiologic convention of favoring estimation

116 instead of hypothesis testing, and also differs from other algorithms for signal detection. For

117 example, the PDOR uses a dynamic denominator, which is different from the Recursive-Least-

118 Square adaptive filter that uses a deterministic input signal (Honig \& Messerschmitt, 1984).

119 Moreover, the numerator is not included in the denominator in the computation of PDOR. This

120 is different from other algorithms that implement the observed-to-expected ratio, in which the

121 expected count is computed by including the observed count under investigation (Kulldorff,

122 2010; Buckeridge, 2008). This study reports on the development of analytic and interpretive

123 protocols based on the PDOR, and their implementation to evaluate surveillance instrumental

124 performance using two simulated outbreaks.

125

\section{Materials and Methods}

127

128 Methodologic background for PDOR

129 The parameter of interest in relating an exposure to a health outcome is the hazard

130 (instantaneous incidence) rate ratio parameter, defined as the ratio of the observed incidence

131 (hazard) rate conditional on one or more covariates $(\mathrm{X})$ to the potential (expected) incidence rate

132 in the counterfactual absence of the covariate(s). At any point in time, the incidence rate of one

133 or more syndromes (or diseases) in a population of individuals exposed to one or more factors is

134 contrasted with what the incidence rate would have been had the factors been absent. The

135 incidence rate ratio (IRR) statistic is an estimate of the IRR parameter, but in a hospital-based

136 surveillance system it is typically not possible to measure average incidence in a day (or period 
137 of days) because the population-at-risk is unknown and ill-defined. Therefore, substitute

138 methods must be employed that allow the approximation of the incidence rate ratio statistic.

139 Table 1, which includes definitions of the components of the following formulas,

140 illustrates the relationship between the IRR and the PDOR utilizing index $(T=t)$ and referent

141 times $\left(\mathrm{T}=\Sigma \mathrm{t}_{\mathrm{i}}(\mathrm{i}=0,1, \ldots, \mathrm{I} ; \mathrm{i}<\mathrm{t})\right)$, where $\mathrm{i}$ represents an individual time point. It is important

142 to note that the statement: $\mathrm{T}=\Sigma \mathrm{t}_{\mathrm{i}}(\mathrm{i}=0,1, \ldots, \mathrm{I} ; \mathrm{i} \neq \mathrm{t})$ can apply to any values of $\mathrm{t}$ under partial

143 exchangeability assumptions. However, in a (near) real-time surveillance program this is

144 constrained to: $\mathrm{T}=\Sigma \mathrm{t}_{\mathrm{i}}(\mathrm{i}=0,1, \ldots, \mathrm{I} ; \mathrm{i}<\mathrm{t})$. It can be shown (Miettinen \& Wang, 1991) that the

145 PDOR, $\{\mathrm{a}(\mathrm{t}) /[\mathrm{a}(\mathrm{t})+\mathrm{b}(\mathrm{t})]\} /\left\{\mathrm{A}\left(\mathrm{t}_{0}, \mathrm{t}_{\mathrm{I}}\right) /\left[\mathrm{A}\left(\mathrm{t}_{0}, \mathrm{t}_{\mathrm{I}}\right)+\mathrm{B}\left(\mathrm{t}_{0}, \mathrm{t}_{\mathrm{I}}\right)\right]\right\}$, can be used to estimate the hazard rate

146 ratio, $\left[\mathrm{a}(\mathrm{t}) / \mathrm{N}_{1}(\mathrm{t})\right] /\left[\mathrm{A}\left(\mathrm{t}_{0}, \mathrm{t}_{\mathrm{I}}\right) / \mathrm{N}_{1}\left(\mathrm{t}_{0}, \mathrm{t}_{\mathrm{I}}\right)\right]$ when: $[\mathrm{a}(\mathrm{t})+\mathrm{b}(\mathrm{t})] / \mathrm{N}_{1}=\left\{\mathrm{A}\left(\mathrm{t}_{0}, \mathrm{t}_{\mathrm{I}}\right)+\mathrm{B}\left(\mathrm{t}_{0}, \mathrm{t}_{\mathrm{I}}\right)\right\} / \mathrm{N}_{0}\left(\mathrm{t}_{0}, \mathrm{t}_{\mathrm{I}}\right)$;

147 note that $\mathrm{a}(\mathrm{t})$ and $\mathrm{b}(\mathrm{t})$ represent syndromic cases and non-syndromic patients at time $=\mathrm{t}, \mathrm{A}\left(\mathrm{t}_{0}, \mathrm{t}_{\mathrm{I}}\right)$

148 and $\mathrm{B}\left(\mathrm{t}_{0}, \mathrm{t}_{\mathrm{I}}\right)$ represent the total number of syndromic cases and non-syndromic patients seen

149 between times $\mathrm{t}_{0}$ and $\mathrm{t}_{\mathrm{I}}$, respectively, and $\mathrm{N}_{1}$ and $\mathrm{N}_{0}$ represent the size of the source populations

150 at times $t$ and time period $\left(t_{0}, t_{I}\right)$, respectively. This translates into the assumption that even in the

151 presence of an outbreak, the overall incidence of visiting a hospital for a syndromic diagnosis

152 among the source population of dogs and cats is the same at index and referent times. This

153 requires a "counterbalancing" of incidence: as the incidence of diagnosing a particular syndrome

154 at $\mathrm{T}=\mathrm{t}$ increases, there must be a commensurate decrease in the incidence of diagnosing other

155 syndromes at $\mathrm{T}=\mathrm{t}$. This assumption is reasonable only when the syndrome of interest under

156 surveillance is rare (e.g., approximately less than 5\%) compared to other diagnoses. Based on

157 the diagnostic outcome proportions (admittedly, not incidence rates) observed, this may be a

158 reasonable assumption in many cases (with the exception, perhaps, of older age group(s)).

159 Achieving such rarity is also facilitated by the kind of patients that this study's hospitals 
160 typically see, because they emphasize preventive care: in the hospital's population, $27.5 \%$ of

161 dogs and $25.2 \%$ of cats (2014 internal data) were reported to be healthy, in contrast to $6.8 \%$ and

$1629.5 \%$ for dogs and cat respectively reported as healthy in the private companion animal practice

163 population, and their patients' ages are relatively younger than those of the potential population

164 of patients (Trevejo, Yang, \& Lund, 2011; Lund et al., 1999). This implies that the sample age

165 distribution might not be representative of age distribution in the source population; thus,

166 stratification by age is indicated.

167 If the rarity assumption holds, then the lesser assumption that the proportion of patients

168 seen without a particular syndrome of interest remains relatively constant over time, also holds:

$169 \mathrm{~b}(\mathrm{t}) / \mathrm{N}_{1}(\mathrm{t})=\Sigma \mathrm{b}\left(\mathrm{t}_{\mathrm{i}}\right) / \mathrm{N}_{0}\left(\mathrm{t}_{0}, \mathrm{t}_{\mathrm{I}}\right)$. This should be reasonable if there are no secular trends in

170 syndromic incidence, which appeared to be empirically true with most hospital data examined

171 prior to commencing this study. The closer $\mathrm{T}=\mathrm{t}$ is to $\left(\mathrm{t}_{0}, \mathrm{t}_{\mathrm{I}}\right)$, the more reasonable this

172 assumption becomes, and the more closely the PDOR corresponds to the hazard rate ratio.

173

174 Background for syndromic definitions

175 A workshop was convened that included external academic experts in epidemiology,

176 nutrition, toxicology, infectious diseases, internal medicine, food safety, and clinical pathology

177 in order to establish a set of syndromes optimal for conducting foodborne disease surveillance in

178 companion animals; none were actually involved in the design of this research or in the

179 preparation of this manuscript. An evaluation of electronic medical nomenclature and data

180 fields was done to identify differences between the data desired from the workshop and the data

181 available in the hospital network database. Thirty-seven syndromic components (i.e., clinical

182 findings, including laboratory results) were selected for further study because these would have 
183 been the most likely to have been recognized in past foodborne disease outbreaks in pet animals,

184 from which the following 10 were adopted for proof-of-concept in the current study: anorexia,

185 elevated alanine aminotransferase (ALT), elevated serum calcium, elevated creatinine, diarrhea,

186 lethargy, a Salmonella-positive fecal sample, seizures, urolithiasis, and vomiting.

187

188 Information technology: data acquisition and transfer

189

An automated and efficient system of data transfer was required for the near real-time

190 design of this system. The following were system analysis and design considerations judged to

191 be of critical importance towards the success of this project: ubiquitous data mapping, high

192 performance, high availability, storage capacity, and timely reporting. To attain "high

193 availability", we sought to design a system that could be adapted for data input from virtually

194 any source. The system thus developed, called "Aberrant Diagnostic Outcome Repository in

195 Epidemiology" (ADORE), was envisioned as a potential center of a future constellation of

196 potential separate or simultaneous information technology sources, including universities,

197 diagnostic laboratories, institutes, government agencies, and private practices. In this research,

198 however, only a single source was utilized.

199 Eight tables containing relevant information were queried in the Banfield database. Each

200 was searched for codes specific to each syndrome. If the syndrome was found in one or more

201 tables, then it was marked as present. Data transferred were restricted to de-identified numbers

202 linking owners and patients, patient demographic information, hospital, number of encounters,

203 and the ten syndromes analyzed in this manuscript. All hospitals used the same electronic

204 medical record software.

205 We initially utilized Microsoft Windows-based programs, including Eclipse for Java 
206 development, MySQL for database architecture, and the UC Davis SmartSite curricular

207 repository for direct data transfer between the information technology center for the hospital

208 network and the University of California, Davis (UC Davis). However, due to security

209 challenges, an alternative approach to real-time transfer was developed. This entailed creating

210 custom scripts at the hospital network's information technology center based on data mapping of

211 the ADORE system and utilizing a secure FTP site; software utilized included SecureFX and

212 MySQL Importer. Data was via secure FTP application transferred from flat (pipe (|) delimited

213 text) files provided by Banfield based on queries from their datasets to our UC Davis server.

214 MySQL Importer tool was utilized to transfer the data from the flat files into tables located in the

215 LOADER Schema. A process called Loader was run against the raw data in these tables, which

216 transformed the data based on the validation and transformation criteria for the project, and

217 inserted into the appropriate ADORE tables or were flagged as exceptions for addressing (Figure $2181)$.

219 Key tables were created at UC Davis for data loading, which included the following 220 database tables: LOADER, EXAMINATIONS, PETIENTS (i.e., pet patients), CLIENTS, 221 LOCATIONS, HOSPITALS, RESULTS, and FINDINGS tables. It was agreed upon that 222 multiple-day sets of data (seven days) would be provided to the UC Davis team to allow data to 223 be transferred in a relatively short period of time. The datasets were transferred to the UC 224 Davis Repository Monday through Friday each week starting on April 25, 2011 and continuing 225 through June of 2011, which allowed approximately six months of data from 2010 (i.e., May 1, 226 through October 20,2010) to be transferred. In total, over 4.2 million patient records with data 227 were imported and used for retrospective surveillance.

228 An external Scientific Advisory Board, comprised of experts in epidemiology, statistics, 
229 and public health, created two foodborne disease outbreak scenarios that were embedded into the

230 system data without disclosure to the UC Davis team. Such blinding was deliberate, in order

231 simulate how the UC Davis team and the ADORE system would perform if surveillance was

232 prospectively implemented in real-time. The outbreaks were designed with the intention of

233 determining whether the team and system could detect them, how long it would take to detect

234 them following their onset, and to measure their magnitude upon detection (Centers for Disease

235 Control and Prevention, 2001). The outbreak data, consisting of simulated medical records of

236 patients, were created by considering the following factors:

237 A. Historical hospital data of the usual prevalence of clinical signs.

238 B. A causative agent or chemical.

239 C. The contaminated food product.

240 D. The proportion of patients consuming the contaminated food product.

241 E. The proportion of patients consuming the contaminated food product exhibiting the $242 \quad$ syndrome.

243 F. The number of hospitals in the affected region.

244 G. A susceptible patient population (e.g., species, age).

245 H. The clinical syndrome appropriate to the food contaminant.

246 I. The production/distribution pattern of the contaminated food, including the amount

247 produced, the proportion of bags affected, the geographic food distribution, and the $248 \quad$ average shelf life.

249 J. The incubation/latency period before syndromic occurrence.

251 PDOR procedure implementation 


\section{Temporal cluster detection}

The specific adaptation of the temporal PDOR procedure used in the current study

255 compares the proportion of patients seen at network hospitals on a particular day that are

256 positive for a particular clinical or laboratory finding with the average proportion of patients

257 positive for the same finding over a seven-day baseline period that ended three months earlier.

258 The use of a seven-day period (which can be modified in the algorithm) allowed for within-week

259 cyclicity of diagnoses, and the use of a three-month lag time (which can also be modified in the

260 algorithm) is suited for a slowly developing foodborne outbreak. The premise behind the

261 temporal cluster detection method was that the proportion of patients diagnosed with individual

262 clinical or laboratory findings should not meaningfully change over a three month period (i.e.,

263 there are no seasonal trends), and that the daily (unobservable) incidence rate over a seven-day

264 period (which is not equivalent to the rate of presentation to a veterinary hospital) is constant.

265 These analyses were performed separately by species (dogs and cat) and in four age strata $(<3$

266 years, 3-7 years, 8-12 years, and 13 or more years), as well as for all ages combined (Figure 2).

267 The following details how the procedure was implemented.

268

\section{Variables and equations}

270

271

272

273

274
A. Number of cases $\left(\mathrm{C}_{\mathrm{i}}\right)$ on current $\left(\mathrm{i}^{\text {th }}\right)$ date. Note that if the same syndromic finding had been noted for the same animal multiple times at the same hospital visit, and if any of these syndromes fell outside the defined threshold range for that finding, this animal was classified as a case. Each animal was counted only once in the analysis for that hospital visit. 
B. Number of hospital visits on current date $\left(\mathrm{N}_{\mathrm{i}}\right)$.

276

C. Diagnostic Outcome Proportion of current date $\left(\mathrm{DOP}_{\mathrm{i}}\right)=\mathrm{C}_{\mathrm{i}} / \mathrm{N}_{\mathrm{i}}$

277

D. Baseline (referent) time window (BW)

278

E. Lag time (1): between current date and the latest date of the baseline time window.

279

F. DOP of baseline $\left(\mathrm{DOP}_{\mathrm{B}}\right)$, computed as the ratio of the total number of cases used for the baseline $\left(\mathrm{C}_{\mathrm{B}}\right)$ to the number of patients seen used for the baseline $\left(\mathrm{N}_{\mathrm{B}}\right)$ in the specified time interval defined by 1 and BW:

282

283

$$
\frac{\sum_{t=i-(l+B W)}^{t=i-l} C_{t}}{\sum_{t=i-(l+B W)}^{t=i-l} N_{t}}
$$

284

285

286

287

288

where $\mathrm{C}_{t}$ and $\mathrm{N}_{t}$ are the number of cases and number of hospital visits, respectively, on date $t$, and $i$ is a time point. If no case occurred during the baseline time window (i.e., $\left.C_{B}=0\right), C_{B}$ was set to 1 .

290

291

$$
\exp \left(\ln (P D O R) \pm D \times \sqrt{\frac{1-D O P_{i}}{C_{i}}+\frac{1-D O P_{B}}{C_{B}}}\right)
$$

where $\exp (\mathrm{)}$ is the exponential function; $\mathrm{ln}$ is the natural logarithmic transformation; $\mathrm{D}=1.28$ for an $80 \% \mathrm{CL}$ and 1.96 for a $95 \% \mathrm{CL}$. Note that if $\mathrm{PDOR}=0$, the $\mathrm{CL}=0$. 
295

296

297

298

299

300

301

302

303

304

305

306

307

308

309

310

311

312

314

315

316

317
An $80 \%$ lower confidence limit (LCL) was selected to increase detection sensitivity in the early stages of an epidemic.

I. If a particular date was missing (e.g., due to hospital closure, such as on Christmas day) in the baseline time window, then the baseline time window was set back one more day, so that the $[\mathrm{i}-(1+\mathrm{BW})-1]^{\text {th }}$ day was used in the computation for $\mathrm{DOP}_{\mathrm{B}}$.

J. If seven out of seven days in the baseline window all had an $80 \% \mathrm{LCL}>1$, the entire week was replaced with the previous baseline window.

K. When a temporal cluster was detected, the equation for an exponentially weighted moving average (MA) was used to smooth plots of the DOP: $E_{t-1}+\alpha\left(O_{t}-E_{t-1}\right)$, where the E's are MA values and O's are observed values. $\alpha$ (weighting factor) is estimated by using $2 /(1+K)$, where $K=$ the number of days in the moving average (i.e., $K=7$ for a weekly moving average). The initial value was set as $\mathrm{E}_{0}=\mathrm{O}_{0}$ (or an average of a time period in the past).

\section{Spatial cluster detection}

The spatial cluster PDOR procedure compared geographic regions in the United States using two levels of granularity: U.S. Census Divisions (USCD) $(n=9)$ and Metropolitan Statistical Areas (MSA) $(\mathrm{n}=39)$ (Figure 3). Each USCD's and MSA's DOP was compared with the average of the other USCDs or MSAs, respectively. The spatial cluster procedure involved two queries:

1) Comparing among the spatial locations to identify spatial clusters (a "first query")

2) Locations that exceeded the predetermined alert level from the first query then 

had a "second query" procedure performed within each of the detected spatial locations from the first query to examine whether there was a within-location temporal cluster.

321

The following are details of how the procedure was implemented (Figure 4):

323

\section{First query variables and equations}

325

326

328

330

331

A. USCD assignments were based on the client's home address, and MSA assignments were based on the hospital location.

B. Each clinical and laboratory finding was separately and unconditionally analyzed. Analysis by USCD was conditional on species and age group, as described above for temporal cluster detection. Analysis of MSA was stratified by species but not by age group.

C. $\mathrm{PDOR}_{\mathrm{i}}=\mathrm{DOP}_{\mathrm{i}} / \mathrm{DOP}_{(\mathrm{A}[-\mathrm{i}])}$, where DOPs are the Diagnostic Outcome Proportions as described above. Let $\mathrm{A}=$ the total number of geographic units (USCD or MSA). $\mathrm{PDOR}_{\mathrm{i}}$ is the ratio of DOP at a particular USCD/MSA (i) and DOP of all other

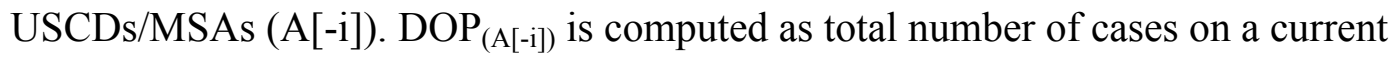
date among all USCDs/MSAs except for location i divided by the total number of hospital visits on a current date in the same locations. If the number of hospital visits for a particular USCD/MSA (i) (i.e., the denominator of DOPi) was zero, $\mathrm{DOP}_{\mathrm{i}}$ and $\mathrm{PDOR}_{\mathrm{i}}=0$.
D. The equation for $\%$ confidence limits (CL) for PDOR is: 


$$
\exp \left(\ln \left(P D O R_{i}\right) \pm D \times \sqrt{\frac{1-D O P_{i}}{C_{i}}+\frac{1-D O P_{A[-i]}}{C_{A[-i]}}}\right)
$$

342

where exp ( ) is the exponential function; In is natural logarithmic transformation; D $=1.28$ for $80 \% \mathrm{CL}$ and 1.96 for $95 \% \mathrm{CL} ; \mathrm{C}_{\mathrm{i}}$ is number of cases on current date at spatial unit $\mathrm{i}$ and $\mathrm{C}(\mathrm{A}[-\mathrm{i}])$ is total number of cases among all locations except for spatial unit i. If the same syndromic finding had been noted for the same animal multiple times at the same hospital visit, and if any of these syndromes fell outside the defined threshold range for that clinical finding, this animal was classified as a case. Each animal was counted only once in the analysis for that hospital visit. Furthermore, if no case occurred in baseline locations (i.e., $\mathrm{C}_{\mathrm{A}[-\mathrm{i}]}=0$ ), then $\mathrm{C}_{\mathrm{A}[-\mathrm{i}]}=1$.

352 If $\operatorname{PDOR}=0$, then $C L=0$. identifying evidence of true positives (real outbreaks) while minimizing the number of false 363

\section{The alert model}

positives, equivalent to increasing both the sensitivity and specificity of the PDOR procedure.

\section{Second query variables and equations}

The second query followed the steps described for the PDOR procedure for temporal cluster detection nested within each spatial cluster where there was evidence of a cluster detected on the first query. The current threshold for entering the $2^{\text {nd }}$ query was set for these analyses to be $C_{i} \geq 5$ and $\mathrm{PDOR}_{i} \geq 1.25$. 
364 To conduct what was essentially an efficient screening process, we developed a five-stage color-

365 coded alert system: green (level 1) was normal, with successively higher levels: blue (level 2),

366 yellow (level 3), orange (level 4), and red (level 5). The stronger the evidence was for temporal

367 or spatial clustering, the higher the alert level.

368 Statistics used in determining alert levels included PDOR, total number of cases, and

369 lower limits of $80 \%$ and $95 \%$ confidence intervals of a PDOR. The scoring system with cutoff

370 values for each statistic is summarized in Table 2. The choice of cutoff values presented here

371 was based on expert opinion and a consensus among project team members. The ADORE

372 system, however, allows users to choose cutoff values and scores.

373 The scoring was first applied to each syndrome, species, and age group combination, and

374 within each combination a sum was computed. The system then evaluated summed scores across

375 strata. If a sum $\geq 5$ occurred in two or more age groups or syndromes, or a sum $\geq 6$ occurred on

376 three or more days in a week, additional scores were added (Table 3). This final score was used

377 to determine alert levels: green: $\leq 8$; blue: 9-12; yellow: 13-15; orange: 16-18; and red: $\geq 19$.

378 Because no age stratification was applied in MSA analysis, the additional score for a sum $\geq 5$

379 occurred in more than one age group was not applied. Therefore, the cutoff values for alert

380 levels were reduced to: green: $\leq 6$; blue: 7-10; yellow: 11-13; orange: 14-16; and red: $\geq 17$.

383 Results

The first aberrant event detected that was found to be a highly plausible outbreak yielded an initial alert on May 15, 2010 (Figures 5, 6, 7). The report generated for the week of May 9 May 13, 2011 (pertaining to the dates May 8 - May 16, 2010) described an event occurring in 
387 dogs of all age groups in the Pacific USCD, and particularly in MSAs 16, 17, 18, 20, and 21

388 within the Pacific USCD. The clinical finding was diarrhea. Had this been real-time

389 surveillance, we would have notified the hospital personnel on May 18, 2010, the date that we

390 would have strongly believed that this was an actual outbreak. This situation continued to be

391 monitored through June 13 - June 17, 2011 (pertaining to dates July 4 - July 18, 2010). The

392 alerts continued unabated through July 10, 2010, after which the outbreak appeared to have

393 resolved. The spatial proximity of the MSAs involved in this aberrant event was striking and

394 strongly suggestive of a point source outbreak. There was no compelling evidence that this

395 outbreak spread to other regions outside the MSAs identified above.

396 Following our submission of a final report of this discovery, the Scientific Advisory

397 Board revealed to the UC Davis team that the aberrant event detected was in fact a provocative

398 challenge (simulated foodborne outbreak). Simulated medical records of dogs in all age

399 categories with diarrhea were randomly assigned to 81 hospitals in California and incorporated

400 into the daily data transfer (Table 4). The outbreak consisted of the following conditions:

401

402 A. Cause: infectious agent causing acute gastrointestinal disease.

403 B. Contaminated product: Dry dog food made by Company " $X$ " in their Reno, NV

$404 \quad$ plant.

405 C. Susceptible population: This food is marketed to all ages, breeds, and sizes of 406 dogs.

407 D. Attack rate: $8 \%$ of hospital network patients consumed this food, and $11 \%$ of

408 those who consumed it were clinically affected.

$409 \quad$ E. Finding for clinically affected animals: diarrhea. 
410

411

412

413

414

415

416

417

418

419

420

421

422

424

425

426

427

428

429

430

431

432
F. Product/distribution information: 1,462 of 2,750 tons $(53 \%)$ of food produced per five days in the plant were distributed to the State of California. The hospital network operates 81 hospitals in California, and the assumption was that the diets were equally distributed throughout the state.

G. The average number of dogs seen at each hospital per day was 20 , and the usual proportion of dogs seen with diarrhea was $3.4 \%$.

H. Dates: The challenge data were embedded starting on May 15, 2010 and continued through July 17, 2010.

9

$$
\text { The second aberrant event found to be a highly plausible outbreak yielded an initial alert }
$$
for August 15, 2010 (Figures 8, 9, 10, 11). Our report for the week of June 27 - July 1, 2011 (pertaining to the dates July 31 - August 19, 2010) described the clinical and laboratory findings as elevated ALT, anorexia, and lethargy. The average PDOR for this time was $3.7+/-2.0$ for ALT, $4.4+/-1.7$ for anorexia, and 3.7+/- 1.2 for lethargy. Both dogs and cats in all age groups were affected. This event was not restricted to a single USCD, but appeared to be national in scope. That is, the temporal alerts were far more compelling in identifying this event than the spatial alerts. The constellation of clinical and laboratory findings was compatible with a hepatotoxic contaminant (such as an aflatoxin), and the enormous rise in the PDORs would have caused us to define this as an actual outbreak by August 18, 2010.

$$
\text { This situation continued to be monitored through the July } 18 \text { - July 22, } 2011 \text { reporting }
$$

period (pertaining to the dates September 24 - October 20, 2010). The red alerts continued unabated through September 26, 2010, after which the outbreak appeared to have resolved. Following our submission of the final report, the Scientific Advisory Board revealed to 
433 the UC Davis Team that the aberrant event detected was in fact a provocative challenge

434 (simulated foodborne outbreak). Simulated medical records of cats and dogs in all age

435 categories with clinical signs typically seen in patients with hepatic disease (e.g., elevated ALT,

436 anorexia, and depression) were randomly assigned to hospitals throughout the U.S. and

437 incorporated into the daily data transfer (Tables 5 and 6). The outbreak was constituted by the

438 following conditions:

439

$440 \quad$ A. Causative agent: aflatoxin.

441 B. Contaminated product: All formulas of dry cat and dog food made in one central

442 plant in the Midwest USA during a two-week period. Cornmeal used in the

443 production of food was contaminated with aflatoxin.

444 C. Susceptible population: All ages, breeds, and sizes of dogs and cats.

$445 \quad$ D. Attack rate: $7.3 \%$ of dogs and $6.7 \%$ of cats were fed this diet, and $30 \%$ of those 446 who consumed it were affected.

447 E. Clinical and laboratory findings for affected animals: Anorexia, depression 448 (lethargy), and icterus (ALT $>100$ in cats, ALT $>118$ in dogs).

449 F. Product/distribution information: The food was distributed from the single plant 450 to the entire country.

451 G. The average number of cats and dogs seen at each hospital per day was 5 and 20, 452 respectively. The usual proportion of cats and dogs seen with elevated ALT was $2.5 \%$ and $2.7 \%$, respectively; with anorexia $4.3 \%$ and $2.5 \%$, respectively; and with depression $1.9 \%$ and $3.5 \%$, respectively. 
H. Dates: The challenge data were embedded starting on August 15 running through September 26, 2010

457

\section{Discussion}

The use of the PDOR as the basis for syndromic surveillance in the current study was

460 effective in detecting two distinct and disparate simulated foodborne outbreaks in companion

461 animals seen at a national network of veterinary hospitals. Alerts were generated by the

462 surveillance system for both outbreaks on the actual day they began and, in the case of the

463 aflatoxin outbreak, for the duration of the challenge period; in the infectious agent outbreak, the

464 alerts were generated continuously for 59 of the 64 days of the outbreak, abating 5 days prior to

465 the end of the challenge period. If these had been real outbreaks, these data would have made it 466 possible to initiate investigations within days of their onset.

467 The methods developed in this study to detect epidemics differ from the pattern

468 recognition approaches of machine learning and artificial intelligence (although the goals are the

469 same), and are adapted from classical epidemiologic methods for studying patient

470 outcome-related data. The PDOR procedure provides a readily interpretable epidemiological

471 measure for quantifying the magnitude of an effect. For example, a PDOR of 3 can be

472 interpreted as a three-fold increase in a Diagnostic Outcome Proportion (DOP) at a point in time

473 compared to a baseline time or period. An additional advantage of comparing proportions

474 instead of counts is that a proportion accounts for variation in the number of hospital visits.

475 Measures often used to accompany such statistics, including p-values and likelihood ratios, are

476 not generated with this approach. Rather, confidence limits are used to quantify precision, and

477 unlike p-values, are interpretable as effect measures. 
The five-level alert system used in our approach considers multiple data-generated output

479

480

481

482

483

484

485

486

487

488

489

490

491

492

493

494

495

496

497

498

499

500

measures. The scores are based on the user-defined importance of each of the output measures and can be modified, based on experience, to calibrate the alert system. Users also have the option of customizing how variables used to estimate PDOR, such as the lag time and baseline period, are defined. For instance, a user can select different lengths of lag time between the current date and the last day of the baseline time window. We employed a 90-day lag time for foodborne outbreak surveillance because we expect this type of outbreak to be gradual in onset. However, with appropriate adjustments, the PDOR procedure is suitable for the surveillance of acute events as well as gradual outbreaks.

The PMR and PRR estimates can serve as the basis for case-control studies that estimate the mortality odds ratio and the reporting odds ratio, respectively (Miettinen \& Wang, 1981; Rothman et al., 2004). Likewise, if individual-level food consumption information is available in the medical record, the PDOR can be adapted to estimate incidence rate ratios by creating a similarly adaptive study design: a diagnostic outcome case-control study. This bears similarity to a study of proportionate diagnostic outcomes, except that comparison diet and geographic groups must be selected for reasons believed a priori to be unrelated to the diet and geographic region of interest. This allows unbiased estimation of the incidence rate ratio using the diagnostic outcome odds ratio. This study design approach will potentially be effective so long as the source of disease in a particular diet is not present in all diets and in all regions represented in the hospital network's database (consistent with standard methodologic criteria for control selection in case-control studies).

A limitation to the indiscriminate use of surveillance arises from false positive and false negative errors. Type I (false positive) errors occur when the decision is made to investigate a 
501 cluster of aberrant events that are either not attributable to any single set of factors or are

502 attributable to factors that are unmeasurable or beyond intervention. Although all syndromes and

503 diseases have causes, not all causes can be investigated, not all outbreaks justify investigation, so

504 the costs and benefits must be weighed when deciding whether or not to investigate. Decisions

505 to move from surveillance to investigation must be carefully made by an appropriate team of

506 medical and epidemiological experts. Such investigations can potentially incur considerable

507 expense and investment of personnel (including hospital) and resources. Type I errors therefore

508 lead to unnecessary and unwarranted investigations. A Type II (false negative) error arises when

509 an epidemic occurs, but is either not detected or not investigated. In the face of an actual

510 epidemic, when such signal- to-noise ratios may not be strong, the methods used in the current

511 study can improve surveillance sensitivity by examining strata of important factors, such as

512 geographic location and age. Such efforts to calibrate surveillance instruments require an

513 understanding of veterinary medicine and cannot be relegated to computer algorithms alone.

514 In summary, the PDOR method provides investigators with a readily interpretable,

515 flexible, and useful tool for detecting disease outbreaks. The ability to customize the various

516 settings and alert levels makes this tool suitable for detection of a multitude of scenarios of

517 disease occurrence. The next logical steps in the application of the PDOR methods would be for

518 the detection of actual disease outbreaks using hospital record data, both retrospectively and in

519 real-time, as well as extending the methods to conduct immediate post-detection etiologic

520 investigations utilizing exposure (i.e. dietary) information in the medical record..

521

522 
523 List of abbreviations: Aberrant Diagnostic Outcome Repository in Epidemiology (ADORE);

524 baseline time window (BW); confidence limits (CL); diagnostic outcome proportion (DOP);

525 exponentially weighted moving average (MA); incidence rate ratio (IRR); information

526 technology (IT); metropolitan statistical area (MSA); proportional mortality ratio (PMR);

527 proportional reporting ratio (PRR); proportionate diagnostic outcome ratio ((PDOR); United

528 States (US); United States census division (USCD); University of California (UC)

529

530

531 Acknowledgements: The authors would like to thank Drs. Sharon Hopkins, Patrick Sullivan,

532 and Lance Waller for developing the simulated outbreaks used to demonstrate proof-of-concept

533 of the methods in this manuscript, and Dr. Rosalie Trevejo for technical assistance.

534 


\section{References}

536

537 American Veterinary Medical Association. 2003. Petcurean Go! Natural pet food recalled.

538 Available at https://www.avma.org/News/JAVMANews/Pages/031215d.aspx (accessed 1 March 539 2016).

540

541 American Veterinary Medical Association. 2012. U.S. Pet Ownership \& Demographics

542 Sourcebook. Available at https://www.avma.org/KB/Resources/Statistics/Pages/Market-

543 research-statistics-US-Pet-Ownership-Demographics-Sourcebook.aspx (accessed 1 March 544 2016).

545

546 Brown CA, Jeong KS, Poppenga RH, Puschner B, Miller DM, Ellis AE, Kang KI, Sum S,

547 Cistola AM, Brown SA. 2007. Outbreaks of renal failure associated with melamine and cyanuric 548 acid in dogs and cats in 2004 and 2007. Journal of Veterinary Diagnostic Investigation 19:525549531.

550

551 Buckeridge DL, Okhmatovskaia A, Tu S, O’Connor M, Nyulas C, Musen MA. 2008.

552 Understanding detection performance in public health surveillance: modeling aberrancy553 detection algorithms. Journal of the American Veterinary Medical Association 15:760-769.

555 Centers for Disease Control and Prevention. 2001. Updated guidelines for evaluating public 556 health surveillance systems. Recommendations from the Guidelines Working Group. Available 557 at http://www.cdc.gov/mmwr/preview/mmwrhtml/rr5013a1.htm (accessed 1 March 2016). 
559 Centers for Disease Control and Prevention. 2015. Update on canine influenza (dog flu) outbreak

560 reported in the Chicago area. Available at http://www.cdc.gov/flu/news/canine-influenza-

561 update.htm (accessed 1 March 2016).

562

563 Day MJ, Breitschwerdt E, Cleaveland S, Karkare U, Khanna C, Kirpensteijn J, Kuiken T, Lappin

564 MR, McQuiston K, Mumford, E, Myers T, Palatnik-de-Sousa CB, Rubin C, Takashima G,

565 Thiermann A. 2012. Surveillance of zoonotic infectious diseases transmitted by small

566 companion animals. Emerging Infectious Diseases 18: online report. Available at

567 http://wwwnc.cdc.gov/eid/article/18/12/12-0664_article (accessed 1 March 2016).

568

569 Dórea FC, Sanchez J, Revie CW. 2011. Veterinary syndromic surveillance: Current initiatives 570 and potential for development. Preventive Veterinary Medicine 101:1-17.

571

572 Drewe JA, Hoinville LJ, Cook AJ, Floyd T, Stärk KD. 2012. Evaluation of animal and public 573 health surveillance systems: a systematic review. Epidemiology and Infection 140:575-590.

574

575 Glickman LT, Moore GE, Glickman NW, Caldanaro RJ, Aucoin D, Lewis HBL. 2006. Purdue 576 University-Banfield National Companion Animal Surveillance Program for emerging and 577 zoonotic diseases. Vector-Borne and Zoonotic Diseases 6:14-23.

578 
579 Halliday JE, Meredith AL, Knobel DL, Shaw DJ, Bronsvoort BMC, Cleaveland S. 2007. A

580 framework for evaluating animals as sentinels for infectious disease surveillance. Journal of the

581 Royal Society Interface 2007, 4:973-984.

582

583 Health Surveillance for UK Companion Animals. 2015. Available at

584 http://www.rvc.ac.uk/VetCompass/Index.cfm (accessed 17 September 2015).

585

586 Hendrick MJ, Goldschmidt MH. 1991. Do injection site reactions induce fibrosarcomas in cats?

587 Journal of the American Veterinary Medical Association 199:968.

588

589 Henning KJ. 2004. Overview of syndromic surveillance. What is syndromic surveillance?

590 Morbidity and Mortality Weekly Report. 53(Suppl):5-11.

591

592 Honig ML, Messerschmitt DG. 1984. Adaptive Filters: Structures, Algorithms and Applications.

593 Dordrecht: Springer.

594

595 Kass PH, Barnes WG Jr, Spangler WL, Chomel BB, Culbertson MR. 1993. Epidemiologic

596 evidence for a causal relation between vaccination and fibrosarcoma tumorigenesis in cats.

597 Journal of the American Veterinary Medical Association 203:396-405.

598

599 Kulldorff M. 2015. SaTScan User Guide for Version 9.4. Available at http://www.satscan.org/ 600 (accessed 1 March 2016).

601 
602 Lund EM, Armstrong PJ, Kirk CA, Kolar LM, Klausner JS. 1999. Health status and population

603 characteristics of dogs and cats examined at private veterinary practices in the United States.

604 Journal of the American Veterinary Medical Association 214:1336-1341.

605

606 Maciejewski R, Tyner B, Jang Y, Zheng C, Nehme RV, Ebert DS, Cleveland WS, Ouzzani M,

607 Grannis SJ, Glickman LT. 2007. LAHVA: Linked animal-human health visual analytics. IEEE

608 Symposium on Visual Analytics Science and Technology (VAST), pp27-34, 2007. Available

609 at http://www.purdue.edu/discoverypark/vaccine/publications.php (accessed 1 March 2016).

610

611 May L, Chretien JP, Pavlin JA. 2009. Beyond traditional surveillance: applying a syndromic

612 surveillance to developing settings - opportunities and challenges. BMC Public Health 9:242

613 DOI: $10.1186 / 1471-2458-9-242$.

614

615 Miettinen OS, Wang JD: An alternative to the proportionate mortality ratio. 1981. American

616 Journal of Epidemiology 114:144-148.

617

618 Milinovich GJ, Williams GM, Clements AC, Hu W. 2014. Internet-based surveillance systems

619 for monitoring emerging infectious diseases. The Lancet Infectious Diseases 14:160-168.

620

621 Puschner B, Reimschuessel R. 2011. Toxicosis caused by melamine and cyanuric acid in dogs

622 and cats: uncovering the mystery and subsequent global implications. Clinical Laboratory

623 Medicine 31:181-99. 
624

625 Rothman KJ. 1990. A sobering start for the cluster busters' conference. American Journal of 626 Epidemiology 132(1 Suppl):S6-13.

627

628 Rothman KJ, Lanes S, Sacks ST. 2004. The reporting odds ratio and its advantages over the 629 proportional reporting ratio. Pharmacoepidemiology and Drug Safety 13:519-523.

630

631 Shaffer LE, Funk J, Rajala-Schultz P, Wallstrom G, Wittum T, Wagner M, Saville W. 2007.

632 Early outbreak detection using an automated data feed of test orders from a veterinary diagnostic

633 laboratory. In: Zeng D, Gotham I, Komatsu K, Lynch C, Thurmond M, Madigan D, Lober B,

634 Kvach J, Chen H: Intelligence and Security Informatics: Biosurveillance 2007, p. 1-10.

635

636 Small Animal Veterinary Surveillance Network. 2015. Available at http://www.savsnet.co.uk/.

637 Accessed on 1 March 2016).

638

639 Trevejo R, Yang M, Lund EM. 2011. Epidemiology of surgical castration of dogs and cats in the

640 United States. Journal of the American Veterinary Medical Association 238:898-904.

641

642 Wójcik OP, Brownstein JS, Chunara R, Johansson MA. 2014. Public health for the people:

643 participatory infectious disease surveillance in the digital age. Emerging Themes in

644 Epidemiology 11:7 DOI: 10.1186/1742-7622-11-7. 


\section{Table $\mathbf{1}$ (on next page)}

Epidemiologic measures of association and observable effect measures in longitudinal syndromic surveillance studies. $\mathrm{T}=$ time, $\mathrm{i}=$ individual time points

$\mathrm{T}=$ time 
1 Table 1: Epidemiologic measures of association and observable effect measures in longitudinal

2 syndromic surveillance studies. $\mathrm{T}=$ time; $\mathrm{i}=$ time points.

\begin{tabular}{|c|c|c|}
\hline Measures & $\mathbf{T}=\mathbf{t}$ & $\mathbf{T}=\Sigma \mathbf{t}_{\mathbf{i}}(\mathbf{i}=\mathbf{0}, \mathbf{1}, \ldots, \mathbf{I} ; \mathbf{I} \neq \mathrm{t})$ \\
\hline Syndromic cases & $\mathrm{a}(\mathrm{t})$ & $\mathrm{A}\left(\mathrm{t}_{0}, \mathrm{t}_{\mathrm{I}}\right)=\Sigma \mathrm{a}\left(\mathrm{t}_{\mathrm{i}}\right)$ \\
\hline $\begin{array}{l}\text { Total patients seen } \\
\text { without syndrome }\end{array}$ & $b(t)$ & $\mathrm{B}\left(\mathrm{t}_{0}, \mathrm{t}_{\mathrm{I}}\right)=\Sigma \mathrm{b}\left(\mathrm{t}_{\mathrm{i}}\right)$ \\
\hline Source population & $\mathrm{N}_{1}(\mathrm{t})$ & $\mathrm{N}_{0}\left(\mathrm{t}_{0}, \mathrm{t}_{\mathrm{I}}\right)$ \\
\hline $\begin{array}{l}\text { Diagnostic } \\
\text { outcome } \\
\text { proportion }\end{array}$ & $\mathrm{a}(\mathrm{t}) /[\mathrm{a}(\mathrm{t})+\mathrm{b}(\mathrm{t})]$ & $\mathrm{A}\left(\mathrm{t}_{0}, \mathrm{t}_{\mathrm{I}}\right) /\left[\mathrm{A}\left(\mathrm{t}_{0}, \mathrm{t}_{\mathrm{I}}\right)+\mathrm{B}\left(\mathrm{t}_{0}, \mathrm{t}_{\mathrm{I}}\right)\right]$ \\
\hline $\begin{array}{l}\text { Incidence rate } \\
\text { (hazard) }\end{array}$ & $a(t) / N_{1}(t)$ & $\mathrm{A}\left(\mathrm{t}_{0}, \mathrm{t}_{\mathrm{I}}\right) / \mathrm{N}\left(\mathrm{t}_{0}, \mathrm{t}_{\mathrm{I}}\right)$ \\
\hline $\begin{array}{l}\text { Hazard rate ratio } \\
\text { (empirical) }\end{array}$ & \multicolumn{2}{|c|}{$\left[\mathrm{a}(\mathrm{t}) / \mathrm{N}_{1}(\mathrm{t})\right] /\left[\mathrm{A}\left(\mathrm{t}_{0}, \mathrm{t}_{\mathrm{I}}\right) / \mathrm{N}_{0}\left(\mathrm{t}_{0}, \mathrm{t}_{\mathrm{I}}\right)\right]$} \\
\hline $\begin{array}{l}\text { Proportionate } \\
\text { diagnostic } \\
\text { outcome ratio } \\
\text { (PDOR) }\end{array}$ & $\multicolumn{2}{|c|}{\mathrm{a}(\mathrm{t}) /[\mathrm{a}(\mathrm{t})+\mathrm{b}(\mathrm{t})]} /\left\{\mathrm{A}\left(\mathrm{t}_{0}, \mathrm{t}_{\mathrm{I}}\right) /\left[\mathrm{A}\left(\mathrm{t}_{0}, \mathrm{t}_{\mathrm{I}}\right)+\mathrm{B}\left(\mathrm{t}_{0}, \mathrm{t}_{\mathrm{I}}\right)\right]\right\}$ \\
\hline
\end{tabular}




\section{Table 2 (on next page)}

Proportionate diagnostic outcome ratio (PDOR) scoring system for temporal analyses and spatial analyses (first query). $\mathrm{LCL}=$ lower confidence limit. 
1 Table 2: Scoring system for temporal and spatial cluster alert models

\begin{tabular}{|c|c|c|}
\hline Statistic & Cutoff value & Score \\
\hline \multirow[t]{5}{*}{$\mathrm{PDOR}^{\mathrm{a}}$} & $<1.25$ & 0 \\
\hline & $1.25-1.99$ & 3 \\
\hline & $2-2.99$ & 5 \\
\hline & $3-3.99$ & 7 \\
\hline & $\geq 4$ & 9 \\
\hline \multirow[t]{2}{*}{ Number of cases } & $<3$ & 0 \\
\hline & $\geq 3$ & 2 \\
\hline \multirow[t]{2}{*}{$80 \% \mathrm{LCL}^{\mathrm{b}}$} & $\leq 1.1$ & 0 \\
\hline & $>1.1$ & 2 \\
\hline \multirow[t]{3}{*}{$95 \% \mathrm{LCL}^{\mathrm{b}}$} & $\leq 0.8$ & 0 \\
\hline & $0.8-1.1$ & 2 \\
\hline & $\geq 1.1$ & 4 \\
\hline Across age groups & $\begin{array}{l}\mathrm{Sum}^{\mathrm{c}} \geq 5 \text { in two or more age } \\
\text { groups }\end{array}$ & 3 \\
\hline Across syndromes & $\begin{array}{l}\text { Sum }{ }^{c} \geq 5 \text { in two or more } \\
\text { syndromes }\end{array}$ & 2 \\
\hline Across days & $\begin{array}{l}\text { Sum }^{c} \geq 6 \text { on three or more } \\
\text { days in a week }\end{array}$ & 4 \\
\hline
\end{tabular}

2 aProportionate diagnostic outcome ratio

3 bower confidence limit of a PDOR

4 bSummed score of PDOR, Number of cases, 80\% LCL, and 95\% LCL

5

6 


\section{Table 3(on next page)}

Proportionate diagnostic outcome ratio (PDOR) scoring system for spatial analyses (second query) with five or more cases and PDOR $\geq 1.25$ on the spatial analysis first query. 
1 Table 3: PDOR scoring system for spatial analyses (second query) with five or more cases and $2 \quad$ PDOR $\geq 1.25$ on the spatial analysis first query 3

Variables

Levels

Score

Notes

\begin{tabular}{l|c|c|l}
\hline \multicolumn{3}{l|}{ Statistics used to determine score for first step (score $\geq 5$ is positive) } \\
\hline PDOR & $\geq 4$ & 9 & \\
\hline & $\geq 3$ & 7 & \\
\hline & $\geq 2$ & 5 & \\
\hline & $\geq 1.25$ & 3 & \\
\hline $80 \%$ LCL & $<1.25$ & 0 & \\
\hline & & & \\
\hline & $>1.1$ & 2 & \\
\hline $95 \%$ LCL & $\leq 1.1$ & 0 & \\
\hline & & & \\
\hline & $>1.1$ & 4 & \\
\hline & $>0.8$ & 2 & \\
\hline & $\leq 0.8$ & 0 & \\
\hline & & & \\
\hline
\end{tabular}

Additional scores added to the first score to determine alert level

Number of days detected within one week
Applied to same syndrome/age stratum/species.

Score applies when sums are $\geq 5$ on $\geq 3$ days in a one week period 


\section{Table 4 (on next page)}

Numbers used to simulate the first aberrant event: an outbreak of diarrhea caused by an infectious agent. Normal average daily prevalence of diarrhea is $3.4 \%$. 
1 Table 4: Numbers used to simulate the first aberrant event: an outbreak of diarrhea caused by an

2 infectious agent. Normal average daily prevalence of diarrhea is $3.4 \%$.

3

\begin{tabular}{l|c|c|c}
\hline Week & $\begin{array}{c}\text { Percent of dogs with } \\
\text { diarrhea caused by } \\
\text { infectious agent }\end{array}$ & $\begin{array}{c}\text { Total percent of dogs } \\
\text { with diarrhea }\end{array}$ & $\begin{array}{c}\text { Total number of } \\
\text { dogs per week } \\
\text { with diarrhea at } \\
\text { each hospital }\end{array}$ \\
\hline 1 & 5.2 & 8.6 & 12 \\
\hline 2 & 2.8 & 6.2 & 9 \\
\hline 3 & 10.2 & 13.6 & 19 \\
\hline 4 & 6.5 & 9.9 & 14 \\
\hline 5 & 13.0 & 4.7 & 73 \\
\hline 6 & 5.7 & 9.1 & 14 \\
\hline 7 & 6.5 & 9.9 & 7 \\
\hline 8 & 1.7 & 5.1 & 5 \\
\hline
\end{tabular}

4

5 


\section{Table 5 (on next page)}

Numbers used to simulate the second aberrant event: an outbreak of hepatic disease caused by aflatoxin contamination. 
1 Table 5: Numbers used to simulate the second aberrant event: an outbreak of hepatic disease

2 caused by aflatoxin contamination. Normal average daily prevalences of anorexia, depression,

3 and ALT elevation are $2.5 \%, 3.5 \%$, and $2.5 \%$, respectively.

4

\begin{tabular}{l|c|c|c|c}
\hline & Week & $\begin{array}{c}\text { Percent of cats } \\
\text { with syndrome } \\
\text { caused by } \\
\text { aflatoxin }\end{array}$ & $\begin{array}{c}\text { Total percent of } \\
\text { cats with } \\
\text { syndrome }\end{array}$ & $\begin{array}{c}\text { Total number of } \\
\text { cats per week } \\
\text { with syndrome at } \\
\text { each hospital }\end{array}$ \\
\hline Anorexia & 1 & 3 & 5 & 2 \\
\hline & 2 & 5 & 7 & 3 \\
\hline & 3 & 7 & 9 & 3 \\
\hline & 5 & 5 & 7 & 2 \\
\hline & 6 & 3 & 5 & 1 \\
\hline Depression & 1 & 1 & 9 & 3 \\
\hline & 2 & 5 & 11 & 5 \\
\hline & 3 & 7 & 14 & 6 \\
\hline ALT elevation & 4 & 10 & 16 & 5 \\
\hline & 5 & 12 & 14 & 4 \\
\hline & 1 & 10 & 11 & 2 \\
\hline & 2 & 7 & 6 & 3 \\
\hline & 3 & 4 & 8 & 4 \\
\hline & 4 & 6 & 10 & 3 \\
\hline & 5 & 8 & 8 & 2 \\
\hline & 6 & 6 & 6 & 5 \\
\hline
\end{tabular}




\section{Table 6(on next page)}

Numbers used to simulate the second aberrant event: an outbreak of hepatic disease caused by aflatoxin contamination. 
1 Table 6: Numbers used to simulate the second aberrant event: an outbreak of hepatic disease

2 caused by aflatoxin contamination. Normal average daily prevalences of anorexia, depression,

3 and ALT elevation are $4.3 \%, 1.9 \%$, and $2.7 \%$, respectively.

4

\begin{tabular}{|c|c|c|c|c|}
\hline & Week & $\begin{array}{l}\text { Percent of dogs } \\
\text { with syndrome } \\
\text { caused by } \\
\text { aflatoxin }\end{array}$ & $\begin{array}{l}\text { Total percent of } \\
\text { dogs with } \\
\text { syndrome }\end{array}$ & $\begin{array}{l}\text { Total number of } \\
\text { dogs per week } \\
\text { with syndrome at } \\
\text { each hospital }\end{array}$ \\
\hline \multirow[t]{6}{*}{ Anorexia } & 1 & 5 & 9 & 13 \\
\hline & 2 & 7 & 11 & 15 \\
\hline & 3 & 10 & 14 & 20 \\
\hline & 4 & 12 & 16 & 22 \\
\hline & 5 & 10 & 14 & 20 \\
\hline & 6 & 7 & 11 & 15 \\
\hline \multirow[t]{5}{*}{ Depression } & 1 & 3 & 5 & 7 \\
\hline & 2 & 5 & 7 & 10 \\
\hline & 3 & 7 & 9 & 12 \\
\hline & 4 & 9 & 11 & 15 \\
\hline & 5 & 7 & 9 & 13 \\
\hline \multirow[t]{7}{*}{ ALT elevation } & 6 & 5 & 7 & 10 \\
\hline & 1 & 4 & 7 & 10 \\
\hline & 2 & 6 & 9 & 12 \\
\hline & 3 & 8 & 11 & 15 \\
\hline & 4 & 6 & 9 & 12 \\
\hline & 5 & 4 & 7 & 10 \\
\hline & 6 & 2 & 9 & 7 \\
\hline
\end{tabular}


1

Schematic of the loader process used to transfer data from a hospital database to a repository used for syndromic surveillance analyses

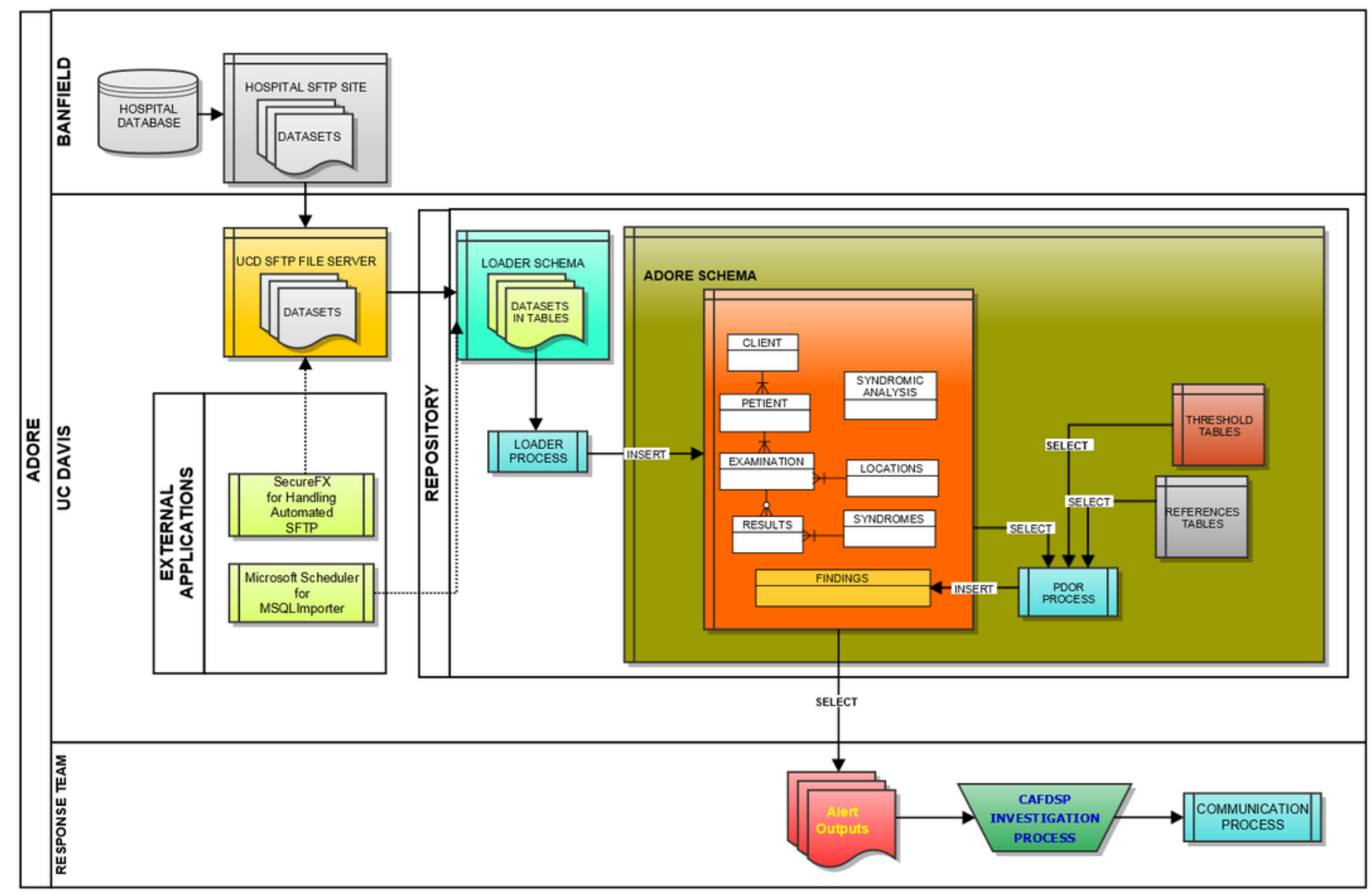


2

Schematic of temporal analysis using the Proportionate Diagnostic Outcome Ratio procedure.

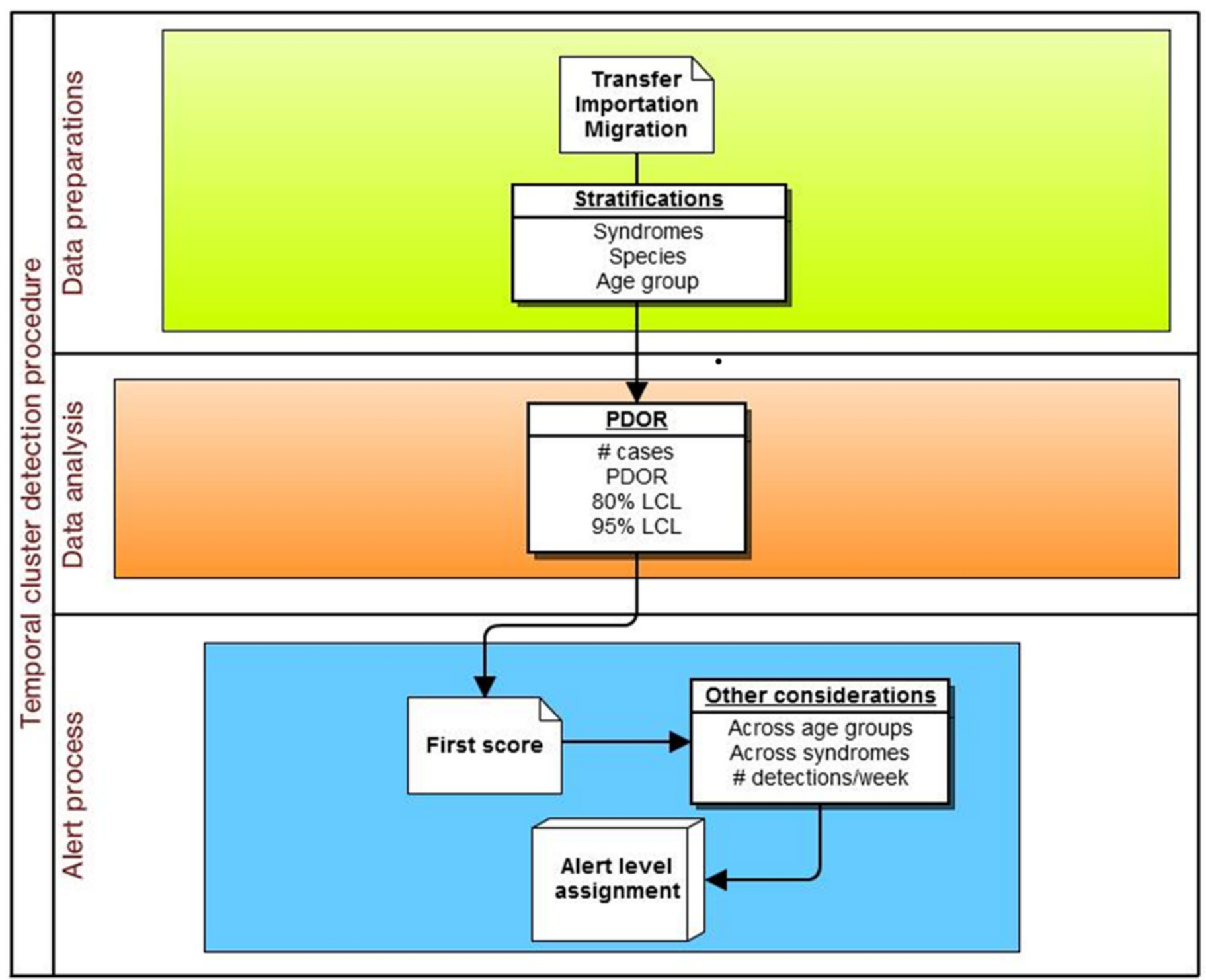


3

Nine US Census Divisions and 39 Metropolitan Statistical Areas (MSA) used with PDOR procedure. Census divisions covers the United States, while MSA encompass regions only where hospitals are located.

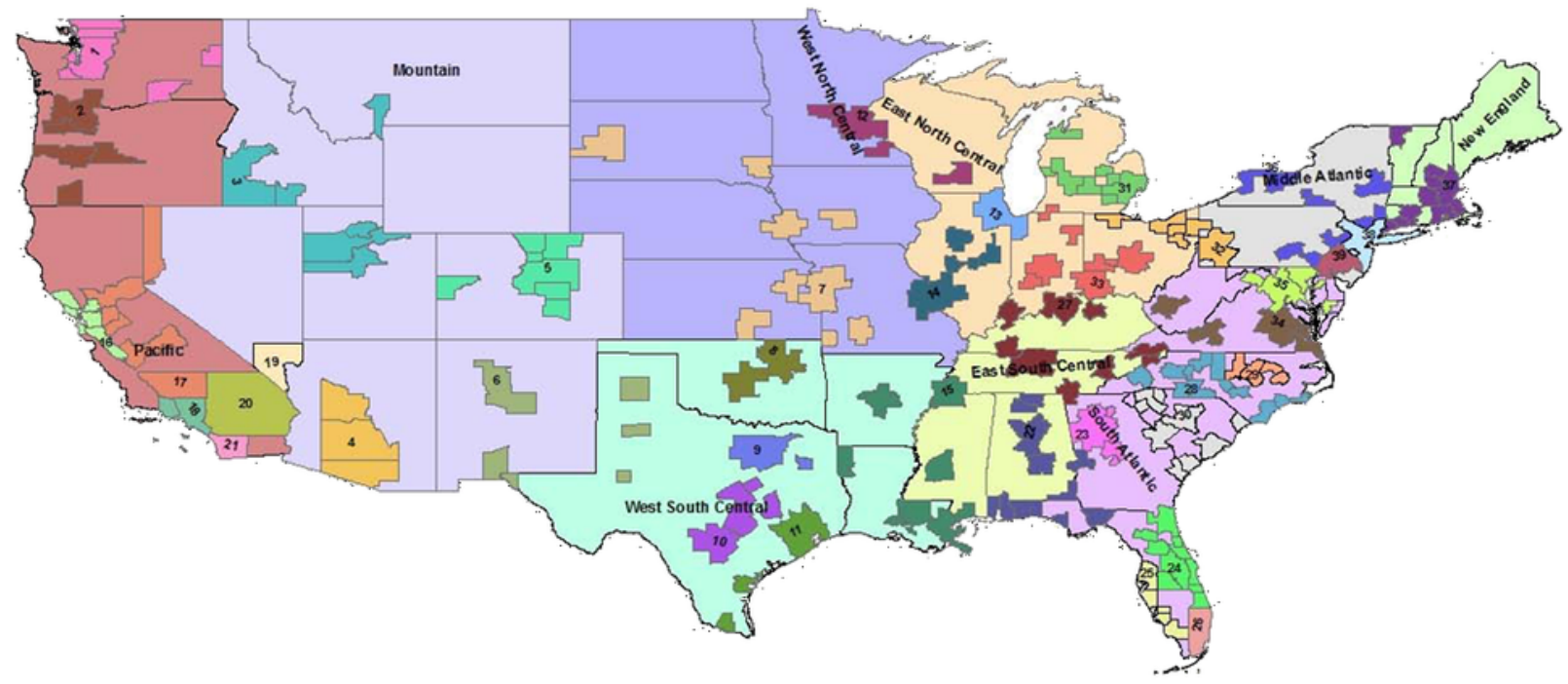


4

Schematic of spatial analysis using the Proportionate Diagnostic Outcome Ratio procedure. 


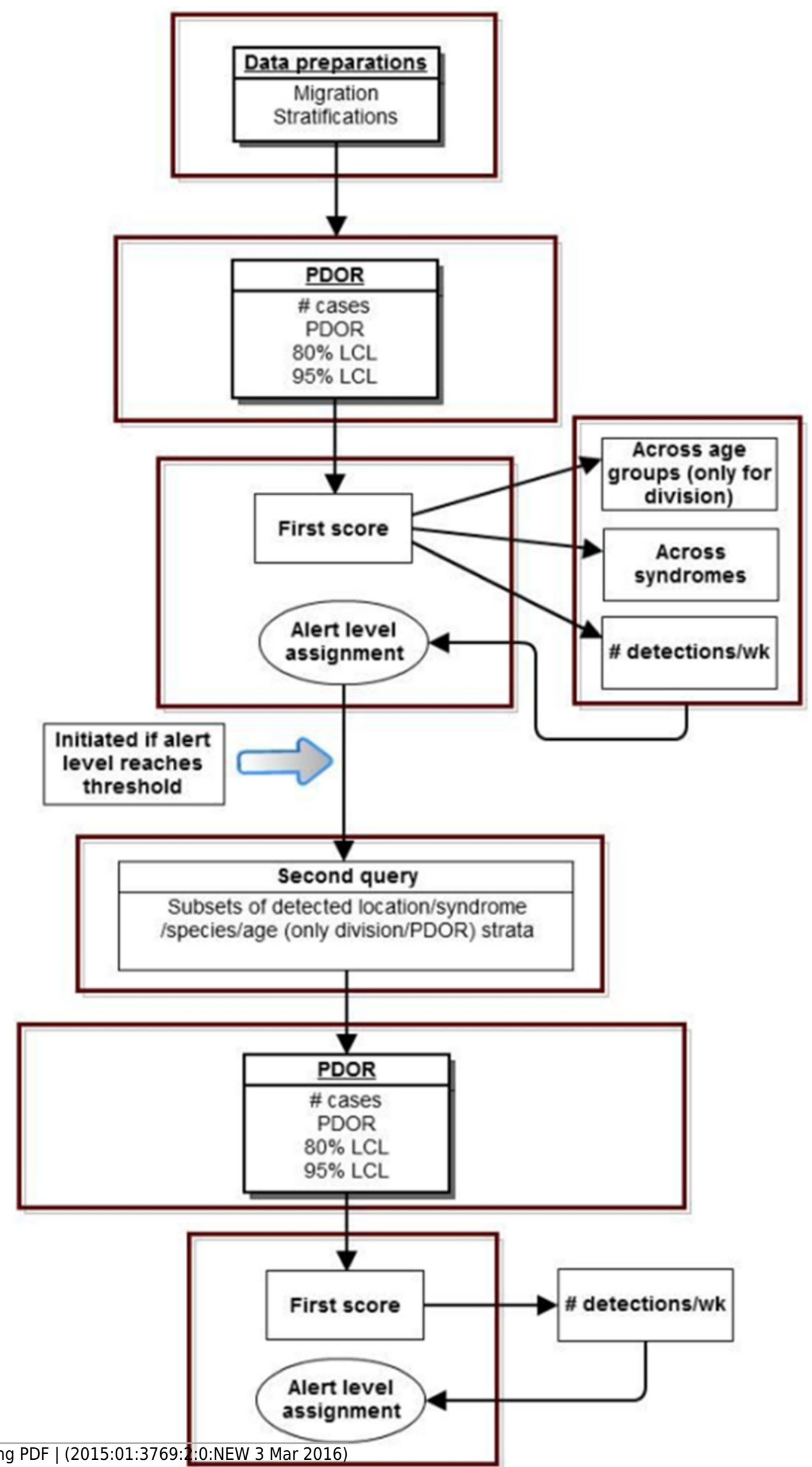


5

Top graph: alert scores for diarrhea in Pacific Census Division by date (spatial analysis, second query). Bottom graph: number of alerts above baseline, by alert color over time (temporal analysis).
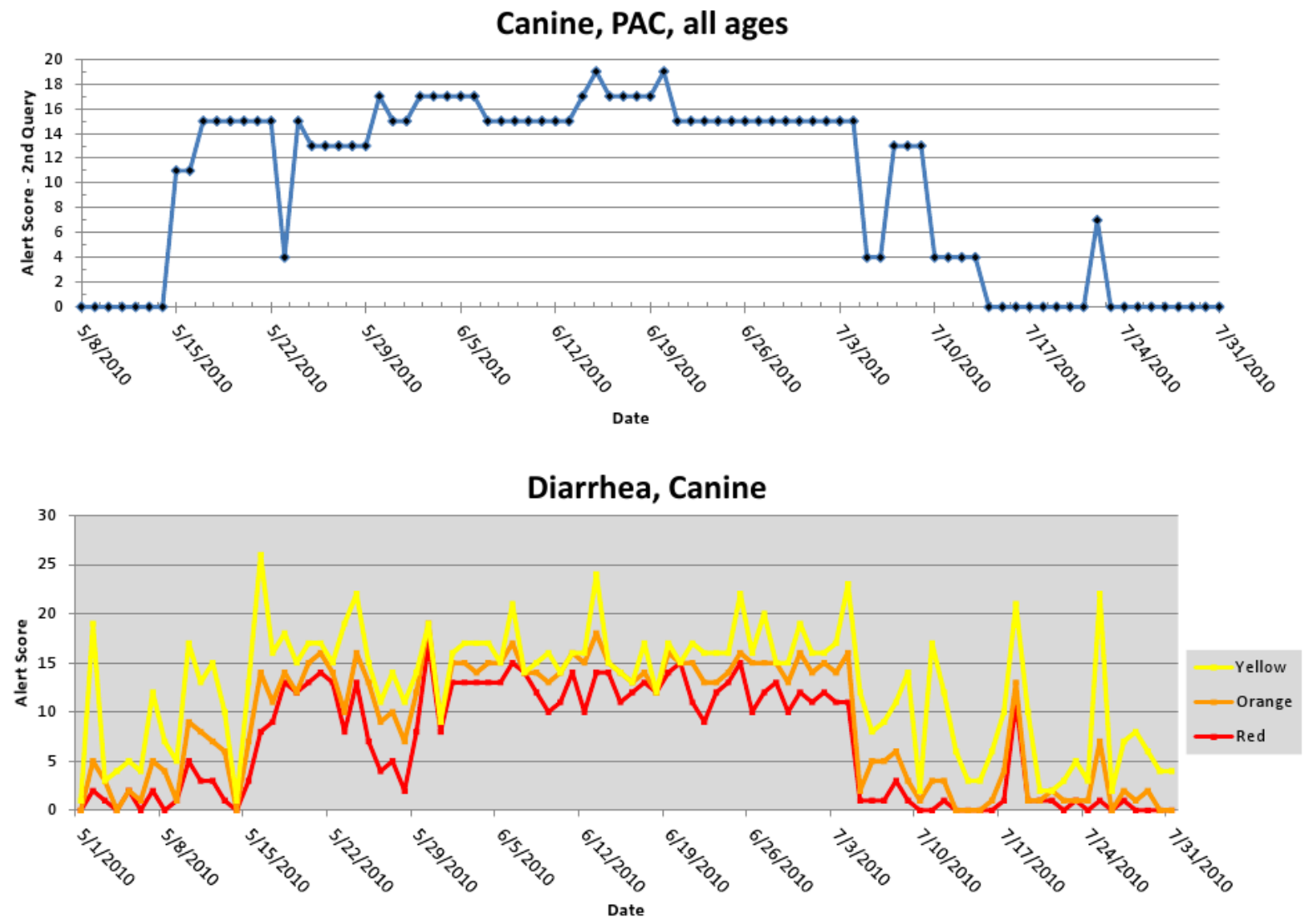
6

Simulated canine infectious agent outbreak in Pacific region. Graph shows diagnostic outcome proportions (DOP) using diarrhea. Red line shows seven day moving average (spatial analysis, second query).

Diarrhea, Canine, all ages combined, PAC

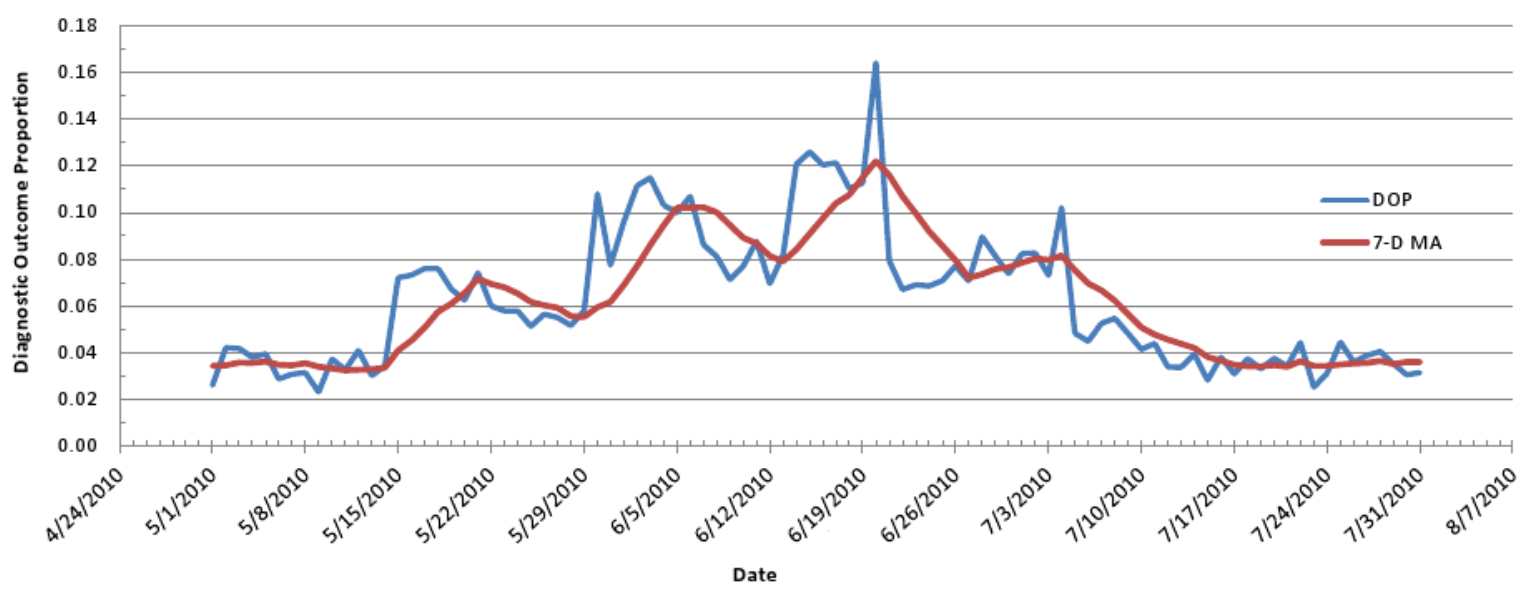


7

Spatial analysis of gastrointestinal disease outbreak over four days. Pacific region begins with no alert (white); then yellow and orange; then yellow, orange, and red; and finally predominantly red.
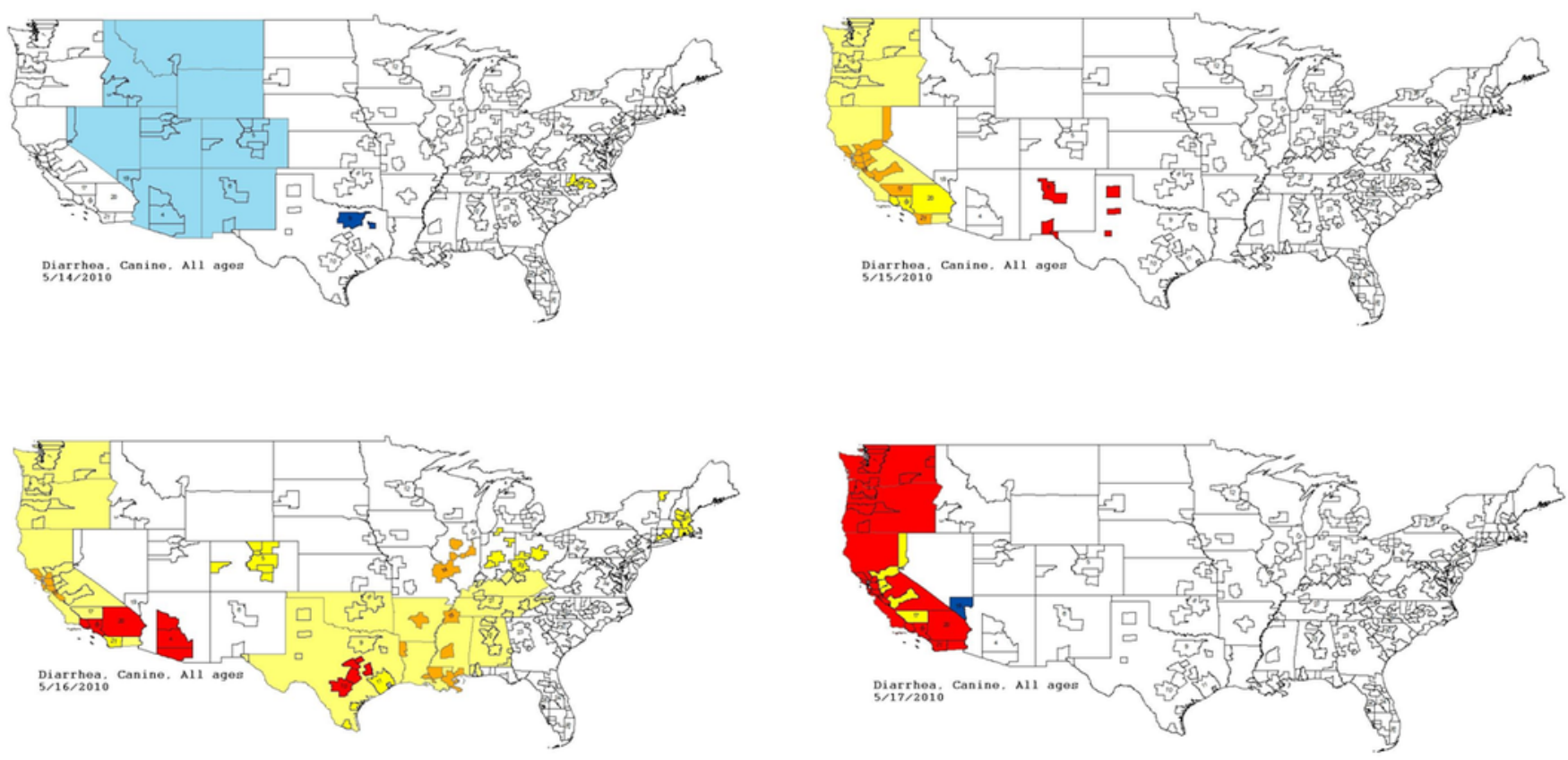
8

Simulated aflotoxicosis outbreak in the US using elevated alanine aminotransferase (ALT) as the clinical finding. Graphs (canine top, feline bottom) show alert scores by date (temporal analysis).
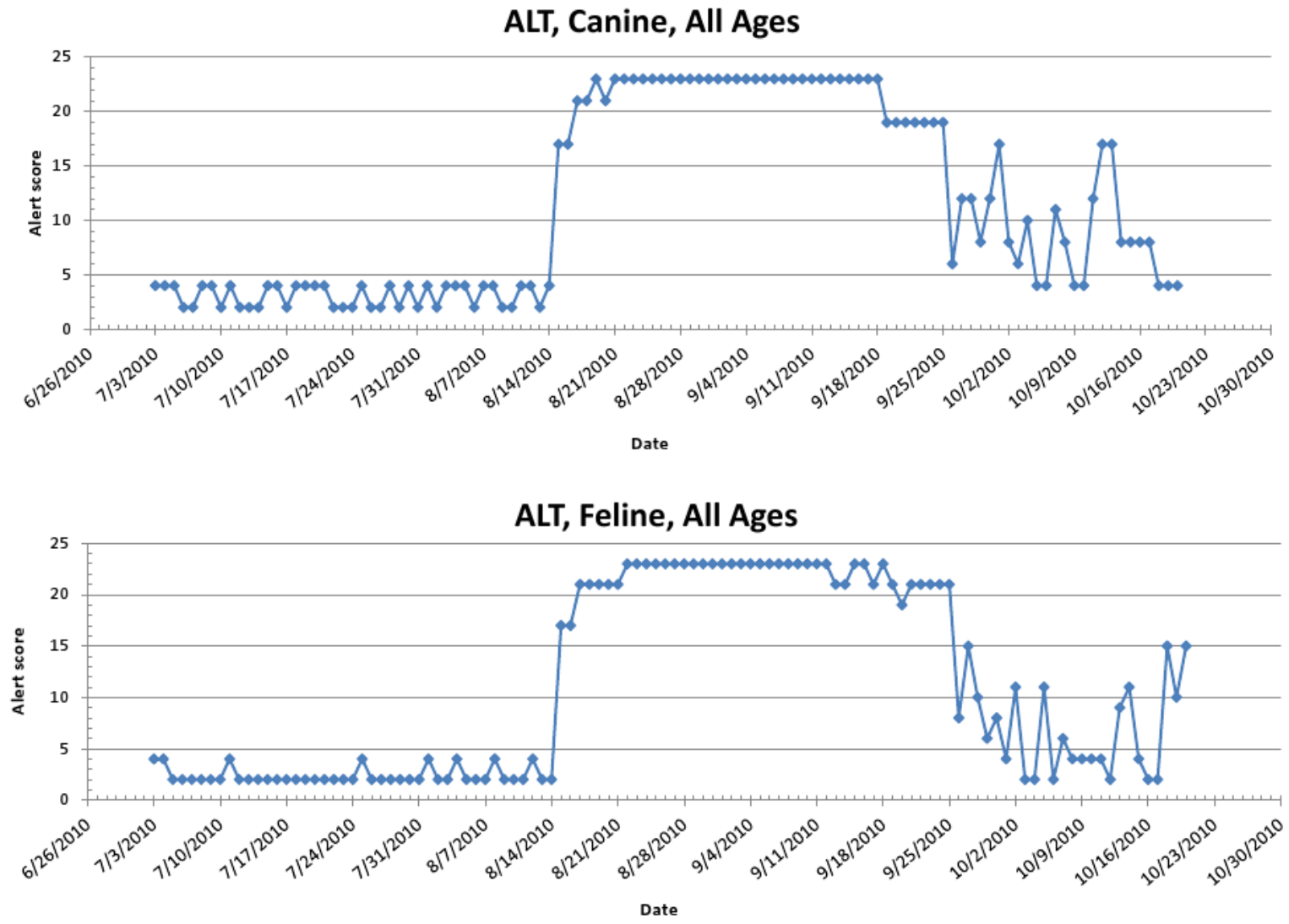
9

Simulated aflotoxicosis outbreak using alanine aminotransferase (ALT) as syndrome. Graphs (canine top, feline below) show number of alerts above baseline, by alert color over time (temporal analysis).
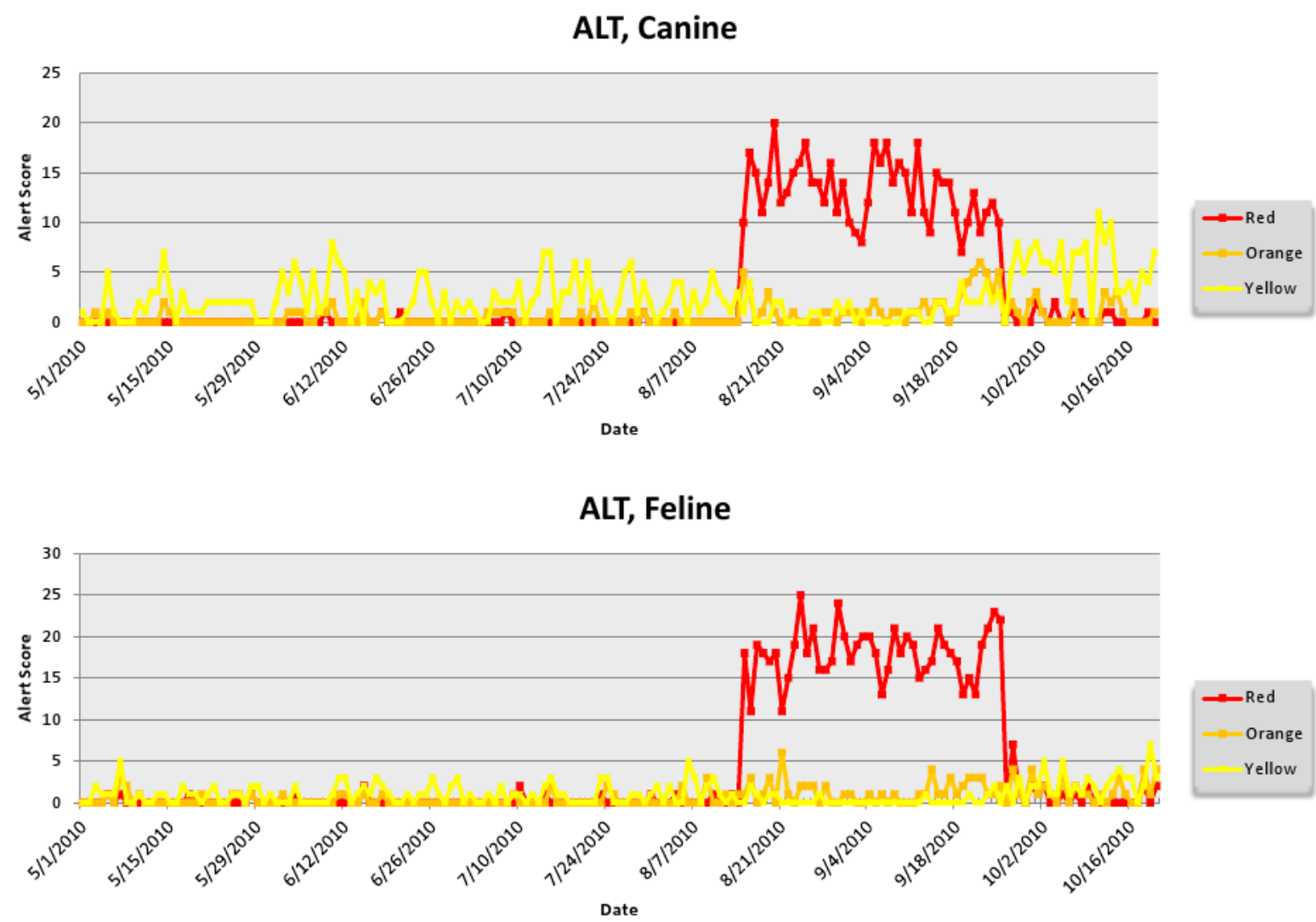
10

Simulated canine aflatoxicosis outbreak using elevated ALT as the syndrome over time. Graph shows diagnostic outcome proportions (DOP); red line shows seven day moving average (temporal analysis).

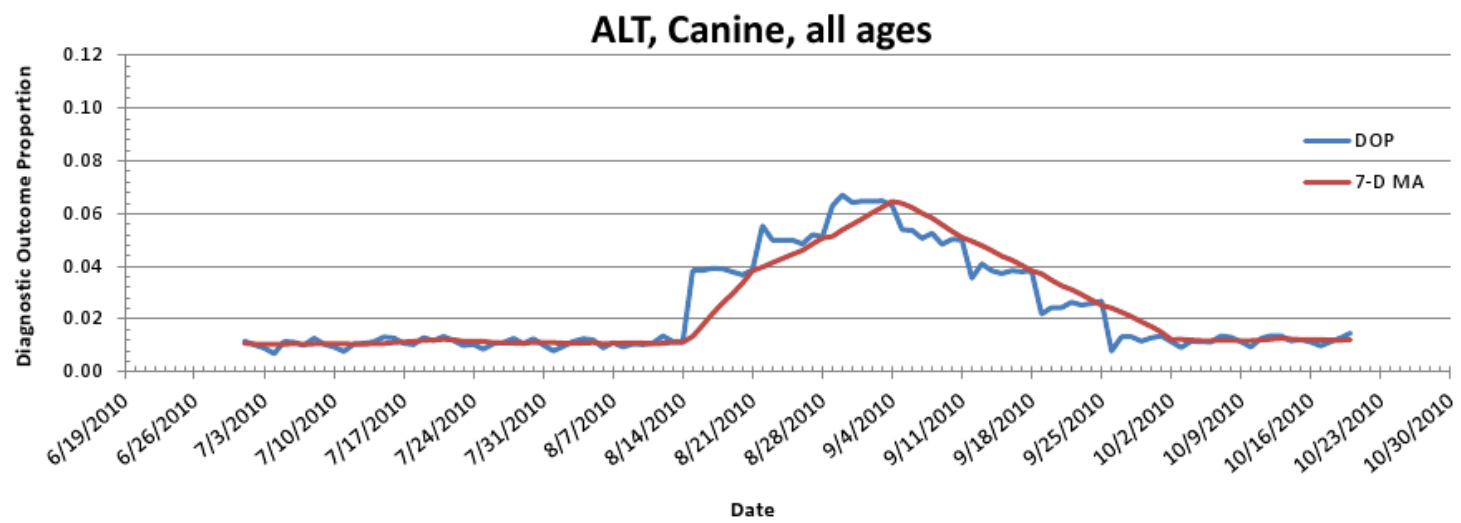

ALT, Feline, all ages

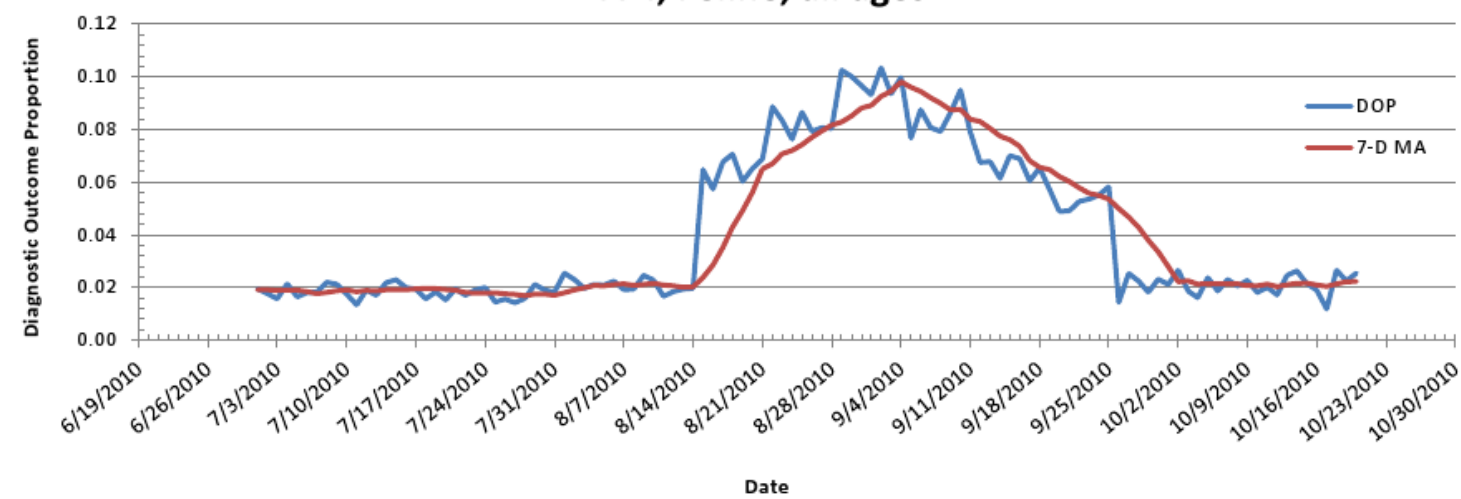




\section{1}

Spatial analysis of simulated aflatoxicosis outbreak in the US over four successive days. The most affected US Census Divisions vary by day, indicating the outbreak is occuring on a national level.
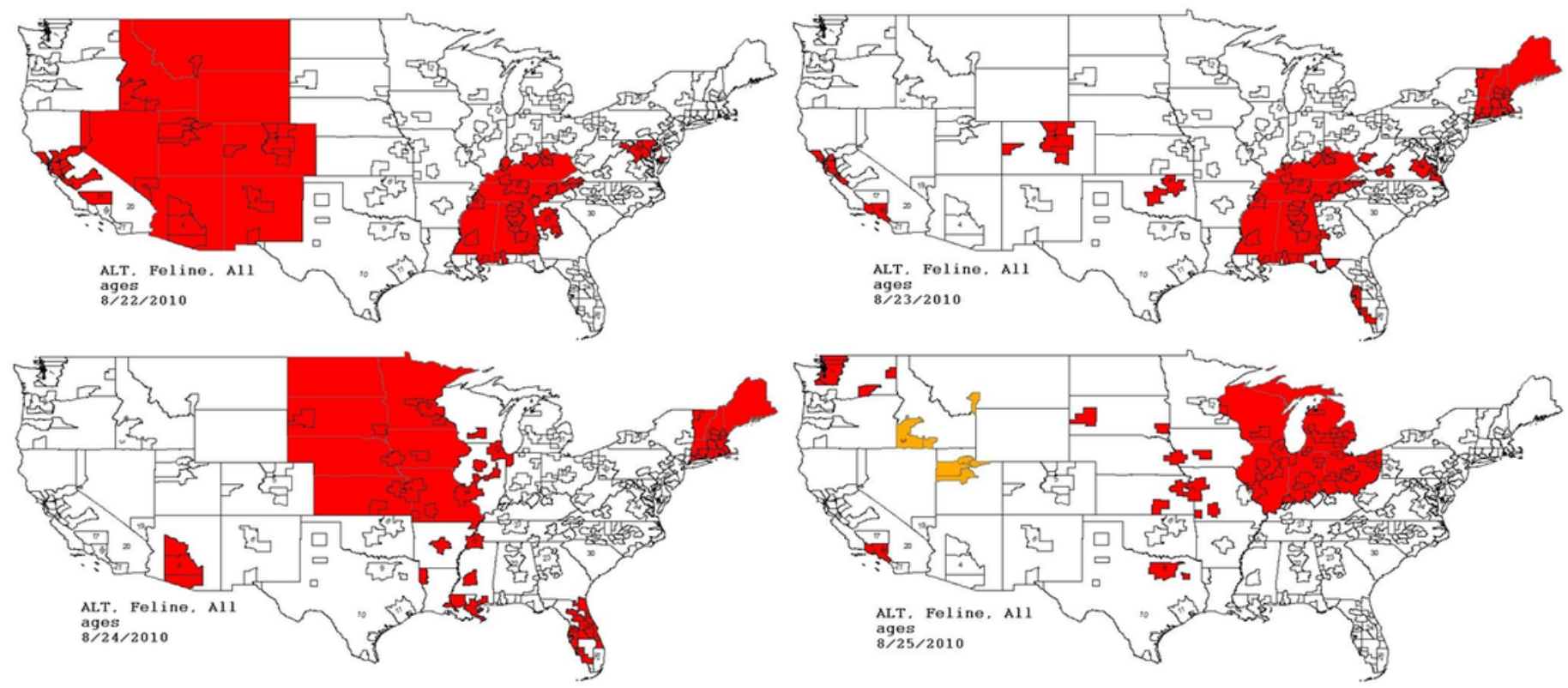